\title{
Lehen Hezkuntzarako kirol-jarduera fisikoko inplikazioaren galdeketa: faktore-analisi baieztatzailea
}

\author{
Questionnaire of engagement in physical-sport activity for Primary Education: \\ confirmatory factor analysis
}

\author{
Iker Izar de la Fuente*, Arantzazu Rodríguez, Naiara Escalante \\ Hezkuntza eta Kirol Fakultatea \\ $\mathrm{UPV} / \mathrm{EHU}$
}

LABURPENA: Aurreko baliozkotze pilotu batetik abiaturik, Lehen Hezkuntzarako kirol-jarduera fisikoko inplikaziorako galdeketaren (IMAF) barne trinkotasuna behin hobetuta faktore-analisi baieztatzailea egiten da. Horretaz gain, itaunketa autokontzeptu fisikoarekin korrelazionatzean kanpo baliotasuneko ebidentziak lortzen dira. Azkenik galdeketaren aldagarritasuna sexuaren eta jarduera fisikoko praktikaren intentsitatearen arabera aztertzen da. Ikerketan Lehen Hezkuntzako seigarren mailako 100 ikaslek (\% 41 neskak; \% 59 mutilak) parte hartu dute, guztiak, 11 edo 12 urte izanez. Erabilitako itaunketak IMAF (kirol-jarduera fisikoko inplikazioa) eta CAF-A (autokontzeptu fisikoa laburbilduta) izan dira. Emaitzek barne trinkotasunean eta azaldutako bariantza totalaren portzentajean hobekuntza erakusten dute. Horretaz gain, itaunketaren egitura proposaturiko eredu tridimentsionalarekin bat dator. Amaitzeko, mutilak eta jarduera kirol-fisikoa intentsitate altuan praktikatzen dutenek inplikazio kirolfisikoan balio alturagoak erakusten dituztela frogatu da.

GAKO-HITZAK: inplikazioa, kirol-jarduera fisikoa, galdeketa, baliozkotzea, Lehen Hezkuntza.

\begin{abstract}
Based on a previous pilot validation, once the internal consistency of the questionnaire of engagement in physical-sport activity (IMAF) for Primary Education is improved, a confirmatory factor analysis is carried out. In addition, external validity evidences are obtained by correlating the questionnaire with the physical self-concept. Finally, the variability of the physical-sport activity engagement regarding the sex and the intensity of the practice of physical activity is analysed. All that with a sample of 100 students of sixth grade of Primary Education (41\% girls; $59 \%$ boys) aged between 11 and $12(M=11.89 ; S D=.314)$. The questionnaires IMAF (physical-sport engagement) and $C A F-A$ (Shorten physical self-concept) have been used. The results of the research certify an improvement in internal consistency and in the percentage of total variance explained. Additionally, the structure of the questionnaire fits the proposed three-dimensional model. Lastly, it has been demonstrated that boys and people who practice physical-sport activity with high intensity show higher values in physical-sport engagement.
\end{abstract}

KEYWORDS: engagement, physical-sport activity, questionnaire, validation, Primary Education.

\footnotetext{
* Harremanetan jartzeko / Corresponding author: Iker Izar de la Fuente. UPV/EHU. Bilakaeraren eta Hezkuntzaren Psikologia Hezkuntza eta Kirol Fakultatea. Juan Ibañez de Sto. Domingo, 1. 01006 Vitoria-Gasteiz. iker.izardelafuente@ehu.eus

Nola aipatu / How to cite: Izar de la Fuente, Iker; Rodríguez, Arantzazu; Escalante, Naiara. (2018). «Lehen Hezkuntzarako kirol-jarduera fisikoko inplikazioaren galdeketa: faktore-analisi baieztatzailea»; Tantak, 30(2), 79-97. (https://doi.org/10.1387/ tantak.19731).

Jasotze-data: 2018/05/11; Onartze-data: 2018/07/10

ISSN 0214-9753 - elSSN 2444-3581 / (c) 2018 UPV/EHU
}

(c) C) Obra hau Creative Commons Atribución 4.0 Internacional-en 
Iker Izar de la Fuente, Arantzazu Rodríguez, Naiara Escalante

\section{SARRERA}

Ikasleriaren parte batek jarduera fisikoa gogokoa du eta horren ondorioz, horretara bideraturiko denborari ahalik eta probetxurik handiena ateratzen saiatzen da. Beste ikasle batzuk, aldiz, jarduera fisikoa saihesten ahalegintzen dira. Zenbait eragileren artean, ikasleriaren ezaugarri psikologikoek kirol-jarduera fisikoko inplikazioan eragina dute (Bevans, Fitzpatrick, Sanchez eta Forrest, 2010). Inplikazioa gehienbat hezkuntzako testuinguruan ikertu da (González, 2010) eta horregatik, eskola-inplikazioa kontzeptu aitzindaritik ondorio gisa sortu izan da kirol-inplikazioa.

Gaur egun, inplikazioa hezkuntzaren psikologiako alorrean interes handiko ikerketa lerro bat bezala finkatu da (Ramos, Fernández, Zuazagoitia, Rodríguez eta Ros, 2015). Tradizioz, eskola-testuinguruetan inplikazioa parte-hartze gogotsu gisa ulertua izan da (Fredricks, Blumenfeld eta Paris, 2004), ingelesez school engagement bezala ezagutzen den konstrukto hori, arrakasta akademikorako beharrezkotzat hartuz (Ros, Goikoetxea, Gairín eta Lekue, 2012). Horrela, ikasleek bere ikaskuntzan egiten duten ahalegina, inbertsioa, interesa eta ardura barnean hartzen dituen prozesu psikologiko gisa definitu da inplikazioa (Marks, 2000). Ildo berean, zereginen desinteresa, bertaratze faltak edota jokaera disruptiboak inplikazio faltarekin erlazionatuta daude (Newmann eta Davies, 1992).

Finn (1989) ikerlariaren parte-hartzea izan zen eredu bidimentsionala, eskola-inplikazioa modu espezifikoan aztertu zuten ikerketa aitzindarien artean nabarmenena. Eredu horretan bi dimentsio bereizten ziren: jarrerazkoa eta emozionala. Lehenengoak ikasle batek eskolan izandako parte-hartzeari erreferentzia egiten dio (erlazioak, bertaratzeak, jarduerak, etab.). Bigarrenak, aldiz, eskolarekiko identifikazioari, hau da, egokitasunezko sentimenduari. Urte berean, Wehlage, Rutter, Smith, Lesko eta Fernándezek (1989) lau dimentsiozko eredu teorikoa aurkeztu zuten: atxikimendua, konpromisoa, parte-hartzea eta konfiantza. Geroago, Leithwood, Mulford eta Silinsen (2004) urte batzuk lehenago Leithwood eta Jantzik (1998) proposatu zuten ereduaren garapena ere nabarmena izan zen. Eredu horretan bi dimentsio klasikoak, parte-hartzea eta eskolarekiko identifikazioa, kontuan hartu ziren.

Inplikazioaren izaera multidimentsionala modu orokorrean onartu den arren, dimentsioen inguruko ezadostasuna oraindik mantentzen da (Ramos, 2015). Hala ere, eredu tridimentsionala da onartuena (Ros eta Zuazagoitia, 2015), Fredricks, Blumenfeld eta Parisen (2004) lana nabarmenduz. Egile horiek school engagement kontzeptua berrikusi eta eguneratu zuten, hiru dimentsio ezberdinduz:

- Jarrerazkoa: ikasleen jokaera behagarriak ikaskuntzarekin eta eskolarekin erlazionatuta (zereginen bukaera, kalifikazioak, noten batezbesteko orokorra, etab.). 
- Afektiboa: eskolarekiko, gelekiko, irakasleriarekiko eta ikaskideekiko interesarekin, balioekin eta sentimenduekin erlazionatutako alderdi emozionalak nahiz ikasleek izandako egoera afektiboak (antsietatea, gogaitasuna, interesa, etab.).

- Kognitiboa: ikaslearen inplikazio psikologikoa ikaskuntzan; ideien, ezagutzen eta gaitasunen menperatze maila; eta ikasteko motibazio intrintsekoa (autoefikazia, onarpen pertzepzioa, itxaropenak, etab.).

Kirol jarduera fisikoko inplikazioa aztertu duten ikertzaileek (Infante, Zuazagoitia, Revuelta eta Echeazarra, 2015) eskola-inplikazioko eredua kirol testuingurura moldatu dute dimentsio berdinak erabiliz. Horrela, dimentsio afektiboa jarduera fisikoarekiko poztasun sentimenduetan oinarritu dute. Kognitiboa jarduera fisikoaren erabilgarritasuna eguneroko eta etorkizuneko bizitzan biltzen dituen ideietan zehaztu dute. Azkenik, jarduera fisikoaren praktikarekin erlazionatutako jarrerekin erlazionatu dute jarrerazko dimentsioa.

Ikertzaile horiek kirol-jarduera fisikoko inplikazioa espezifikoki neurtzeko lehenengo galdeketa garatu zuten: Cuestionario de Implicacion en Actividad Físico-Deportiva (IMAF; Infante, et al., 2015). Hala ere, galdeketa hori soilik Bigarren Hezkuntzarako diseinatu zen. Horrela, Lehen Hezkuntzan kirol-jarduera fisikoaren inplikazioa neurtzeko tresnarik ez zegoen, kirol-ohiturak ezartzen diren adin tarte horretan ezagutza gabezia handia egonez.

Horren ondorioz, Izar de la Fuente, Rodríguez eta Revueltak (2018) IMAF neurketa tresnaren Lehen Hezkuntzarako lehenengo baliozkotze pilotua garatu zuten. Baliozkotze horretan, galdeketa originala 22 itemetik 12 itemera murriztu zen, guztiak .40 gutxieneko asetasuna mantenduz (Lozano eta De la Fuente, 2009; Morales, 2011) eta inplikazioaren hiru dimentsioetan ezberdinduz. Azaldutako bariantza totaleko portzentajean \% 44.54 lortu zen. Barne trinkotasunari dagokionez, .70ko Cronbach-eko alfa lortu zen. Hala ere, lehenengo ikerketa horren eztabaidan aipatu zen moduan, galdeketaren item baten (i15) ezabaketaren bitartez barne trinkotasunaren ia $.07 \mathrm{ko}$ hobekuntza lortu zitekeen. Hortaz, baliozkotze horren datuak onargarriak izan arren, galdeketa fidagarriagoa eta egokiagoa bihurtzeko neurriak hartu behar dira. Horretaz gain, lorturiko egitura tridimentsionala faktore analisi baieztatzaile baten bitartez egiaztatu behar da.

Kirol-jarduera fisikoko inplikazioa ikerketa lerro oso berritzailea denez, orain arte oso gutxi ikertu izan da. Ondorioz, ia ez dago ebidentzia enpirikorik kirol-jarduera fisikoko inplikazioren eta aldagai soziopertsonalen (sexua edo jarduera fisikoko praktikaren intentsitatea, besteak beste) arteko erlazioen inguruan. Hala ere, badago aldagai soziopertsonal horiek erlazionatzen dituen informazio asko duen eta kirol-jarduera fisikoko inplikazioarekin teorikoki oso hurbila den konstrukto bat: autokontzeptu fisikoa. Aldagai hori honela definitu daiteke: «la concepción que se posee acerca 
de los rasgos corporales y/o apariencia física de uno mismo, de la condición (forma) física, la fuerza y las habilidades físico-deportivas.» (Esnaola, 2005, 134. or.). Gainera, lau dimentsioz osatuta dago: erakargarritasun fisikoa, indarra, trebetasun fisikoa eta gaitasun fisikoa (Esnaola, 2005; Goñi, Ruiz de Azúa eta Rodríguez, 2006).

Nahiz eta korrelazioak positiboak edo negatiboak diren adostuta ez egon, ikerketa guztiek kirol-jarduera fisikoaren eta autokontzeptu fisikoaren arteko korrelazio esanguratsuak baieztatzen dituzte (Infante, Rodríguez, Fernández eta Goñi, 2007). Horretaz gain, eskola testuinguruetan inplikazioa eta autokontzeptua korrelazionatuta daude (Ros, 2009) eta azken horrek jarrerazko nahiz emoziozko inplikazioa aurreikusteko gaitasuna duela ezaguna da (Rodríguez, Ramos, Ros eta Zuazagoitia, 2018). Gainera, autokontzeptua eskola-inplikazioarekin elkartutako aldagai bitartekari gisa identifikatu da (Rodríguez et al., 2016). Hori dela eta, ikerketa honetan kirol inplikazioaren eta autokontzeptu fisikoaren arteko erlazioak aurkitzea espero da.

Aurretik aipaturiko aldagai soziopertsonalei dagokionez, autokontzeptu fisikoaren izaera generoaren arabera aldatzen dela jakina da (Elosua, 2004), ezberdintasunak gizonen aldekoak izanez (Goñi, Ruiz de Azúa eta Rodríguez, 2004; Crain, 1996; Ayora, García eta Rubio, 1997; Garduño eta Ramírez, 2001). Jarduera fisikoaren praktikari erreferentzia eginez, autokontzeptu fisikoan praktikaren edo praktika-ezaren araberako ezberdintasun esanguratsuak topatu dira (Ruiz de Azúa, Zulaika, Palacios eta Goñi, 2002). Orokorrean, jarduera fisikoaren praktika modu positiboan erlazionatzen da autokontzeptu fisikoarekin, bi norantzako erlazioa izanez (Balaguer, Atienza eta Duda, 2012; Biddle, Whitehead, O'Donovan eta Nevill, 2005). Era berean, praktika horren intentsitateari dagokionez, autokontzeptu fisikoarekin eraginezko erlazio positibo bat dago (Crocker, Eklund eta Kowalski, 2000; Jaakkola eta Washington, 2011; Inchley, Kirby eta Currie, 2011): intentsitatea zenbat eta altuagoa izan, orduan eta auto-pertzepzio fisiko positiboagoa (Revuelta, Esnaola eta Goñi, 2016). Hala ere, kirol-jarduera fisikoko inplikazioan sexuaren edo jardueraren intentsitatearen araberako ezberdintasunak ez dira aztertu autokontzeptu fisikoan egin den moduan. Hortaz, aipatu berri diren emaitzak kontuan harturik, ikerketa honetan kirol-jarduera fisikoko inplikazioan sexuaren eta jarduera fisikoko intentsitatearen araberako ezberdintasunak aurkitzea espero da.

Kirol-jarduera fisikoko inplikazioa Lehen Hezkuntzan aztertzea beharrezkoa da ezaugarri hori nola sustatu jakin ahal izateko. Tamalez, adin tarte horretarako soilik lehenengo baliozkotze pilotua garatu da (Izar de la Fuente, Rodríguez eta Revuelta, 2018), oraindik amaitzeke dagoena. Izan ere, barne trinkotasuna hobetu daiteke eta galdeketaren egitura baieztatuko lukeen faktore-analisi baieztatzailea garatu. Horretaz gain, kirol-jarduera fisikoko inplikazioaren ezberdintasunak sexua eta jarduera fisikoa- 
ren intentsitatea bezalako aldagai soziopertsonalen arabera ezezagunak dira oraindik. Horien ezagutza oso erabilgarria izango litzateke ikasleen inplikazioa sustatu nahi izatekotan.

Egoera hori dela kontuan harturik, ikerketa honen helburuak bi dira: (a) kirol-jarduera fisikoko inplikazioaren Lehen Hezkuntzarako galdeketaren (IMAF) barne trinkotasun indizeak hobetzea eta barne egitura tridimentsionala (inplikazio kognitiboa, jarrerazkoa eta afektiboa) baieztatzea. Behin azken egitura lortuta, (b) galdeketaren aldagarritasuna aztertzea hainbat aldagai soziopertsonalen (sexua eta kirol-jarduera fisikoaren intentsitatea) arabera.

\section{METODOA}

\section{Partaideak}

Ikerketa honetan Gasteizko bi eskolatako 100 ikaslek parte hartu zuten, guztiak Lehen Hezkuntzako seigarren mailakoak, 11 edo 12 urte izanez $(\mathrm{M}=11.89 ; \mathrm{DT}=.314)$. Laginaren \% 59 mutilak ziren eta gainerako \% 41 neskak, talde orekatuak izanez $\left(\chi^{2}=.41 ; p>.05\right)$. Bi ikastetxeetako bat publikoa zen, maila sozioekonomiko baxukoa. Bestea, itunpekoa zen, maila ertain-altukoa. Laginketaren aukeraketa modu intzidentalean egin zen.

\section{Aldagaiak eta neurketa tresnak}

Ikerketa honetan hurrengo aldagai soziopertsonalak erabili dira:

- Sexua. Aldagai dikotomikoa. Parte-hartzaileei sexua zehaztea eskatu zitzaien (emakumea edo gizona).

- Kirol-jarduera fisikoaren intentsitatea. Parte-hartzaileei praktikatzen zuten jarduera fisikoaren intentsitatea zehaztea eskatu zitzaien (baxua, ertaina edo altua).

Jarraian ikerketa honetan erabilitako neurketa tresnak aurkezten dira.

- Kirol- eta jarduera fisikoko inplikazioa neurtzeko, Lehen Hezkuntzara bideratuta dagoen «Cuestionario de Implicación en Actividad Físico-Deportiva» (Izar de la Fuente et al., 2018) erabili zen, jatorrizko IMAF galdeketan (Infante et al., 2015) jatorria duena. Galdeketa hori 12 itemez osatuta dago, inplikazioaren hiru dimentsioetan (afektiboa, kognitiboa eta jarrerazkoa) antolatuta. Item bakoitzari 5 graduko ( $1=$ inoiz ez; 5 = beti) Likert eskala baten bidez erantzuten da. Barne trinkotasunari dagokionez, .70ko Cronbach-eko alfa lortu zuen. 
- Autokontzeptu fisikoa neurtzeko Cuestionario de Autoconcepto Físico Abreviado (CAF-A; Rodríguez, Axpe eta Goñi, 2015) erabili zen. Galdeketa hori 8 itemez osatuta dago; ebaluatzen duen autokontzeptu fisikoaren dimentsio bakoitza (erakargarritasun fisikoa, indarra, trebetasun fisikoa eta gaitasun fisikoa) 2 itemez osatuta dago. Itemak 5 graduko $(1=$ gezurra; 5 = egia) Likert eskala baten bidez erantzuten dira. Galdeketa autokontzeptu fisikoaren berezko egitura tetradimentsionalera egokitzen da .93ko fidagarritasun konposatu (McDonald-en Omega) eta batezbesteko bariantza laburtu (.63) bikain batekin.

\section{Prozedura}

Ikerketa honen egileak ikastetxeekin harremanetan jarri ziren bertako zuzendaritzarekin izandako bilera baten bidez ikerketaren parte hartzea proposatzeko. Behin parte-hartzea onartuta, ikerketan parte hartu nahi zuten ikasleen gurasoek edo tutoreek sinatu beharreko baimen informatua bidali zitzaien. Baimen horretan ikerketaren helburuen, erabiliko ziren galdeketen, borondatezko parte-hartzearen eta datuen konfidentzialtasunaren nahiz prozesuaren edozein mementotan horien erabilera baliogabetzeko eskubidearen berri ematen zitzaien.

Ikertzaileak eurak joan ziren ikastetxeetara, baimen informatua sinatuta entregatu zuten ikasleei galdeketak pasatzera. Galdeketak betetzen hasi aurretik parte hartzaile guztiei haien anonimatua ziurtatuko zitzaiela eta ikerketan parte hartzea borondatezkoa zela informatu zitzaien. Eskalak betetzeko beharrezko denbora 30-40 minutukoa izan zen.

\section{Datuen analisia}

Galdutako balioen (\% 1) tratamendurako, Markov Monte Carlo katetik eta itxaropen maximizazio algoritmotik abiatuz item horretarako gutxi gorabeherako hurbileko puntuazioa atera zen, parte hartzaileek emandako erantzun guztietan oinarrituta.

Analisietan hurrengo pausoak jarraitu ziren:

A) Faktore egitura aztertzailearen estimazioa Windowserako SPSS 20 pakete estatistikoarekin egindako datuen biraketa zeiharrarekin iteratutako ardatz nagusien faktorizazio metodoaren bidez eta unitatea baino autobalio handiagoko faktore guztien ateratzea.

B) Windowserako AMOS 24 pakete estatistikoarekin egindako galdeketaren faktore-analisi baieztatzailea. Teknika horrekin, ontasun indize ezberdinen konbinazioaren bidez probatzen ari diren ereduen adostasun enpirikoa alderatzen da. 
Tradizioz, aztertzen den lehenengo indizea Khi-karratu estatistikoa $\left(\chi^{2}\right)$ da, zeinen balio ez-esanguratzuek $(p>.05)$ ereduaren adostasuna adierazten duten. Hala ere, indize hori laginaren tamainaren arabera oso aldakorra denez, ez da bere erabilera gomendatzen ontasun indize bakarra bezala. Horren ondorioz, indize hori hurrengo lerroetan azalduko direnekin batera aztertu behar da (Carretero-Dios eta Pérez, 2005; Rodríguez, Droguett eta Revuelta, 2012).

Ikerketa honetan erabilitako indizeak, alde batetik, GFI (Goodness of Fit Index), CFI (Comparative Fit Index), IFI (Incremental Fit Index) eta TLI (Tucker-Lewis Index) izan dira. Horien balioak 90 baino altuagoak izan behar dira egokitzat hartzeko (Schumacker eta Lomax, 2010). Beste aldetik, SRMR (Standarized Root Mean Square Residual) eta RMSEA (Root Mean Square Error of Approximation) indizeak erabili dira. Horien balioak, aldiz, .08 baino baxuagoak direnean egokitzat hartzen dira eta .05 baino baxuagoak direnean, onak (Browne eta Cudeck, 1993, Hu eta Bentler, 1999; Lacobucci, 2010). Azkenik, AIC (Akaike Information Criterion) eta CAIC (Consistent Akaike's Information Criterion) indizeak erabili dira proposaturiko ereduen artean onena zein zen identifikatzeko, balio baxuenak bilatuz (Tomás eta Oliver, 1997).

C) Galdeketaren barne trinkotasunaren (Cronbach-en alfa) eta fidagarritasunaren (fidagarritasun konposatua eta laburtutako batezbesteko bariantza) kalkulua.

D) Kanpo baliotasuneko ebidentzien lorpena: korrelazioen kalkulua autokontzeptu fisikoaren inguruko erantzunen bidez.

E) Joera nagusiko puntuazioen aldea gizonezkoen eta emakumezkoen erantzunen artean eta jarduera fisikoko praktikaren intentsitatearen arabera. Sexuaren inguruko analisiak independenteak diren bi laginentzako batezbestekoen alderaketa arrunt baten bidez egin zen, T-Student probarekin. Intentsitatearen aldagaian bi kategoria baino gehiago egonda (baxua, ertaina eta altua), bariantza faktorialaren analisia (ANOVA) erabili zen. Ondoren, balizko ezberdintasunak aztertzeko helburuarekin, bariantzen homogeneotasunaren arabera Tukey-eko edota Games-Howell-eko alderaketa anizkunak (posthoc) burutu ziren.

Korrelazioetan nahiz batezbestekoen konparaketetan proba parametrikoak erabili ziren zenbait taldetan 30 subjektu baino gutxiago egon arren; izan ere, horiek balizko normaltasuneko urratzeen aurrean irmoak dira (Chok, 2010; Edgell eta Noon, 1984; Schmider, Ziegler, Danay, Beyer eta Bühner, 2010). 


\section{EMAITZAK}

\section{Faktore-analisi aztertzailea}

Lehen Hezkuntzarako IMAF galdeketaren lehenengo baliozkotze saiakeraren (Izar de la Fuente et al., 2018) ondorioetan aipatu zen moduan, item baten (i15) ezabaketaren bitartez barne trinkotasunean ia .07ko hobekuntza lor zitekeen.

Hori dela eta, dimentsionalitatearen analisiarekin hasteko, 15. itema baztertu da. Ondoren, faktore analisi aztertzailearekin hasi aurretik, KaiserMeyer-Olkin (KMO) indizea eta Bartlett-en froga proba egiaztatzen dira. Emaitzek balio egokiak adierazten dituzte, KMO indizea .70 baino balio handiagoak adieraziz $(\mathrm{KMO}=.771)$ eta Bartlett probaren adierazgarritasuna .05 baino txikiagoa izanez $(\mathrm{p}=.000)$. Horretaz gain, azaldutako bariantza totalaren portzentajea \% 46.09koa da.

Indize horiek egokiak izan arren, komunalitateetan (1. taula) 12. itemak balio baxuegia aurkezten du (.192) (Hair, Anderson, Tatham eta Black, 2004). Hori dela eta, hurrengo faktore analisi aztertzailerako itema baztertu da, prozesua errepikatuz.

\section{1. taula}

Komunalitateak

\begin{tabular}{lc}
\hline & Ateratzea \\
\hline Afektua_04 & .664 \\
Afektua_01 & .631 \\
Afektua_10 & .666 \\
Afektua_07 & .395 \\
\hline Kognizioa_17 & .436 \\
Kognizioa_11 & .377 \\
Kognizioa_22 & .283 \\
\hline Jarrera_05 & .771 \\
Jarrera_12 & .192 \\
Jarrera_19 & .442 \\
Jarrera_08 & .213 \\
\hline
\end{tabular}

Analisiarekin hasi aurretik bai KMO indizea (.783) bai Bartletten probaren adierazgarritasuna $(p=.000)$ egokiak direla frogatzen da. Azaldutako bariantza totalaren portzentajeari dagokionez, $\%$ 47.25era heldu da. Datu horiek egokiak izanda, bigarren faktore analisia aurrera eramaten da (ikusi 2. taula). 
2. taula

2. analisi faktoriala

\begin{tabular}{l|ccc}
\hline & \multicolumn{3}{|c}{ Faktorea } \\
\cline { 2 - 4 } & 1 & 2 & 3 \\
\hline Afektua_04 & .803 & & \\
Afektua_01 & .727 & & \\
Afektua_10 & .730 & & \\
Afektua_07 & .578 & & \\
\hline Kognizioa_17 & & .691 & \\
Kognizioa_11 & & .538 & .716 \\
Kognizioa_22 & & .488 & .408 \\
\hline Jarrera_05 & & & .436 \\
Jarrera_19 & & & \\
Jarrera_08 & & & \\
\hline
\end{tabular}

Bigarren taulan ikusi daitekeenez, lehenengo faktorean (afektua), bigarrenean (kognizioa) eta hirugarrenean (jarrera), item guztiak zuzenak dira, bere faktorean kokatuta daudelako eta pisu faktorial egokia daukatelako (>.40) (Lozano eta De la Fuente, 2009; Morales, 2011). Hortaz, hori izango litzateke galdeketaren behin betiko egitura, 10 itemez osaturik-; bi gutxiago, abiapuntuarekin alderatuta.

\section{Faktore-analisi baieztatzailea}

Ikerketa honetan galdeketarako hiru egitura ezberdin alderatu dira. Bi eredu, M1 eta M2 tridimentsionalak inplikazioaren parametro teorikoen arabera ezarri dira, hau da, alderdi kognitiboen, emozionalen eta jarrerazkoen baturaren arabera. Bi eredu horien ezberdintasuna itemen kopura da, lehenengoa (M1) 10 itemez osatuta dago eta bigarrena (M2) aldiz, 11 itemez (faktore-analisi aztertzailean bazterturiko jarrera_12 itema mantendu da). Bi eredu horiekin batera alderatzeko proposatu den hirugarren eredua (M3) dimentsio bakarrekoa da, hau da, dimentsio bakar batean batzen ditu inplikazioaren alderdi guztiak. Emaitzak 3. taulan aurkezten dira. 
Iker Izar de la Fuente, Arantzazu Rodríguez, Naiara Escalante

3. taula

Kirol-jarduera fisikoko inplikazio ereduen ontasun indizeak

\begin{tabular}{cccccccccc}
\hline Eredua & $\chi^{2}(\mathrm{gl})$ & GFI & CFI & IFI & TLI & SRMR & RMSEA & AIC & CAIC \\
\hline M1 & $44.22(31)$ & .923 & .949 & .952 & .926 & .684 & .066 & 92.22 & 178.75 \\
M2 & $57.61(38)$ & .911 & .929 & .933 & .897 & .689 & .072 & 113.61 & 214.56 \\
M3 & $81.54(35)$ & .853 & .820 & .827 & .769 & .911 & .116 & 121.54 & 193.64 \\
\hline
\end{tabular}

Legenda: $\mathrm{M} 1$ = Tridimentsionala 10 item; M2 = Tridimentsionala 11 item; M3 = unidimentsionala.

Eredu bakoitzaren ontasun indizeak aztertuz gero, lehenik eta behin, hirugarren eredua, dimentsio bakarrekoa $\left(\chi^{2}(35)=81.54\right.$, $p<.05 ; \mathrm{GFI}=.853 ; \mathrm{CFI}=.820 ; \mathrm{IFI}=.827 ; \mathrm{TLI}=.769 ; \mathrm{SRMR}=.911 ;$ RMSEA $=.116)$, beste bi ereduekin $($ M1 eta M2) alderatuta esanguratsuki desberdina dela ondoriozta daiteke. Horrela, onargarriak diren indizeen mugetatik urrun dago. Gainerako bi ereduei dagokienez, lehenengoak, 10 itemez osaturiko eredu tridimentsionalak $\left(\chi^{2}(31)=44.22\right.$, $p<.05 ; \mathrm{GFI}=.923 ; \mathrm{CFI}=.949 ; \mathrm{IFI}=.952 ; \mathrm{TLI}=.926 ; \mathrm{SRMR}=.684 ;$ RMSEA $=.066)$, bigarren eredua, 11 itemeko tridimentsionala $\left(\chi^{2}(38)=57.61, p<.05 ; \mathrm{GFI}=.911 ; \mathrm{CFI}=.929 ; \mathrm{IFI}=.933 ; \mathrm{TLI}=.897\right.$; SRMR $=.689 ;$ RMSEA $=.072$ ), baino balio egokiagoak adierazten ditu.

Horren ondorioz, 10 itemeko eredu tridimentsionala (M1) indize onenak izanda, hori aukeratzen da kirol-jarduera fisikoko inplikazioaren galdeketaren barne egitura adierazteko. Gainera, AIC eta CAIC indizeek lehenengo eredua (M1) nabarmentzen dute eredu onena gisa, bi indizeen artean balio baxuenak izanik $(\mathrm{AIC}=92.22 ; \mathrm{CAIC}=178.75)$.

\section{Barne trinkotasuna eta fidagarritasuna}

Galdeketaren barne trinkotasuna Cronbach-eko alfaren bitartez aztertu da, $\alpha=.76$ ko balioa lortuz, zeinak gomendatzen den gutxieneko .70 gainditzen baitu (Nunnally eta Bernstein, 1995).

Fidagarritasunaren azterketarako, fidagarritasun konposatuko koefizientea (Composite Reliability Coefficient, CRC) erabili da. Hori, egitura-ekuazioen ereduan lorturiko itemen asetasunen bitartez kalkulatzen da, Cronbach-eko alfa baino aukera egokiagoa izanez (Peterson eta Kim, 2013). Koefizienteak .86ko balioa lortu zuen, gomendatzen den gutxieneko .70 gaindituz (Nunnally, 1967). Fidagarritasun konposatua interpretatzeko laburtutako batezbesteko bariantzarekin (Average Variance Extracted, AVE) konbinatu behar da. Azken hori fidagarritasunerako beste adierazle bat da eta bere balioak .50 baino baxuagoak ez izatea gomendatzen da 
(Hair, Black, Babin, Anderson eta Tatham, 2006). Ikerketa honetan, AVEren balioa .41 koa izan zen, mugatik hurbil egonez.

\section{Kanpo baliotasuneko ebidentziak}

Kanpo baliotasuneko ebidentziak lortzeko, irizpide eta diskriminatze baliotasunak albo batean utziz, baliotasun konbergentea aurrera eraman da. Baliotasun mota horretan, kirol-jarduera fisikoko inplikazioaren galdeketa aldagai berdina edo antzekoa neurtzen duen beste batekin konparatzen da ea korrelazio maila egokirik ba ote duen. Kasu honetan, kirol-jarduera fisikoaren inplikazioarekin erlazionaturiko proba gehiagorik ez dagoenez, autokontzeptu fisikoarekin egitea erabaki da, teorikoki oso erlazionatuta dagoen konstruktoa baita. Jarraian bi galdeketen arteko korrelazioen emaitzak aurkezten dira (ikusi 4. taula).

\section{4. taula}

Kirol-jarduera fisikoko inplikazioaren eta autokontzeptu fisikoaren arteko korrelazioak

\begin{tabular}{|c|c|c|c|c|c|}
\hline & & Afektua & Kognizioa & Jarrera & $\begin{array}{c}\text { Kirol } \\
\text { inplikazioa } \\
\text { totala }\end{array}$ \\
\hline Indarra & $\begin{array}{c}\text { Pearson } \\
\text { P }\end{array}$ & $\begin{array}{l}.043 \\
.669\end{array}$ & $\begin{array}{l}.216^{*} \\
.031\end{array}$ & $\begin{array}{l}.240^{*} \\
.016\end{array}$ & $\begin{array}{l}.211^{*} \\
.036\end{array}$ \\
\hline $\begin{array}{l}\text { Erakargarritasun } \\
\text { fisikoa }\end{array}$ & $\begin{array}{c}\text { Pearson } \\
\text { P }\end{array}$ & $\begin{array}{l}.304 * * \\
.002\end{array}$ & $\begin{array}{l}.178 \\
.077\end{array}$ & $\begin{array}{l}.248^{*} \\
.013\end{array}$ & $\begin{array}{l}.328 * * \\
.001\end{array}$ \\
\hline $\begin{array}{l}\text { Trebetasun } \\
\text { fisikoa }\end{array}$ & $\begin{array}{c}\text { Pearson } \\
\text { P }\end{array}$ & $\begin{array}{c}-.276 * * \\
.005\end{array}$ & $\begin{array}{r}-.106 \\
.294\end{array}$ & $\begin{array}{r}-.116 \\
.249\end{array}$ & $\begin{array}{c}-.223 * \\
.026\end{array}$ \\
\hline Gaitasun fisikoa & $\begin{array}{c}\text { Pearson } \\
\text { P }\end{array}$ & $\begin{array}{l}.387^{* * * *} \\
.000\end{array}$ & $\begin{array}{l}.223 * \\
.026\end{array}$ & $\begin{array}{l}.519 * * * \\
.000\end{array}$ & $\begin{array}{l}.526 * * * \\
.000\end{array}$ \\
\hline $\begin{array}{l}\text { Autokontzeptu } \\
\text { fisiko orokorra }\end{array}$ & $\begin{array}{c}\text { Pearson } \\
\text { P }\end{array}$ & $\begin{array}{l}.214^{*} \\
.033\end{array}$ & $\begin{array}{l}.262 * * \\
.008\end{array}$ & $\begin{array}{l}.461 * * * \\
.000\end{array}$ & $\begin{array}{l}.424 * * * \\
.000\end{array}$ \\
\hline
\end{tabular}

* $p<.05 ; \quad * * p<.01 ; \quad * * * p<.001$.

Taulan azaltzen den moduan, bai aldagai bakoitzaren dimentsioen artean bai aldagai totalen artean korrelazioak daude. Horrela, indarrak modu positiboan korrelazioan jartzen du kognizioarekin $(r=.216)$, jarrerarekin $(r=.240)$ eta kirol inplikazio totalarekin $(r=.211)$. Erakargarritasun fisi- 
koak modu positiboan korrelazioan jartzen du afektuarekin $(r=.304)$, jarrerarekin $(r=.248)$ eta kirol inplikazio totalarekin $(r=.328)$. Trebetasun fisikoari dagokionez, soilik afektuarekin $(r=-.276)$ eta inplikazio totalarekin $(r=-.223)$ korrelazioan jartzen du, modu negatiboan gainera. Gaitasun fisikoak modu positiboan korrelazioan jartzen du inplikazioaren dimentsio guztiekin (afektua, $r=.387$; kognizioa, $r=.223$; jarrera, $r=.519$ ) baita totalarekin $(r=.526)$, autokontzeptu fisiko orokorrak egiten duen modu berean (afektua, $r=.214$; kognizioa, $r=.262$; jarrera, $r=.461$; inplikazio totala, $r=.424$ ). Espero zen moduan, korrelazioak badaude baina horiek ez dira altuegiak, konstruktoak erlazionatuta egon arren, ezberdinak direlako. Horren ondorioz, kanpo baliotasuneko emaitzak egokitzat har daitezke.

\section{Galdeketaren aldagarritasunaren azterketa}

Ikerketaren bigarren helburua Lehen Hezkuntzarako balidatu den kiroljarduera fisikoko inplikazioaren galdeketaren aldagarritasuna aldagai soziopertsonalen arabera (sexuaren eta kirol-jarduera fisikoko praktikaren intentsitatea) aztertzea zen.

Horrela, jarraian, jarduera fisikoko inplikazioa parte-hartzaileen sexuaren (ikusi 5. taula) eta jarduera fisikoko praktikaren intentsitatearen (ikusi 6. taula) araberako azterketa aurkezten da.

5. taula

Ezberdintasunak kirol-jarduera fisikoaren inplikazioan sexuaren arabera

\begin{tabular}{c|l|ccccc}
\hline \multicolumn{2}{c}{} & $\mathrm{n}$ & $\mathrm{M}$ & $\mathrm{SD}$ & $\mathrm{t}$ & $\mathrm{P}$ \\
\hline \multirow{2}{*}{ Afektua } & Neska & 41 & 17.34 & 2.97 & & \\
& Mutila & 59 & 18.37 & 2.57 & -1.847 & $.068^{*}$ \\
\hline \multirow{2}{*}{ Kognizioa } & Neska & 41 & 13.36 & 1.89 & -2.281 & $.026^{*}$ \\
& Mutila & 59 & 14.15 & 1.36 & & \\
\hline \multirow{2}{*}{ Jarrera } & Neska & 41 & 9.51 & 3.24 & -1.308 & $.194^{*}$ \\
& Mutila & 59 & 10.35 & 3.12 & & \\
\hline \multirow{2}{*}{$\begin{array}{c}\text { Imnplikazio } \\
\text { totala }\end{array}$} & Neska & 41 & 40.21 & 6.33 & -2.274 & $.025^{*}$ \\
\hline$* p<.05 ; * *$ & Mutila & 59 & 42.88 & 5.32 & & \\
\hline
\end{tabular}

Taulan ikus daitekeenez, soilik kognizioaren dimentsioan eta kiroljarduera fisikoko inplikazio totalean daude ezberdintasun esanguratsuak, 
horien balioak adierazgarriak baitira (kognizioa $t=-2.281 ; p=.026$; kirol-jarduera fisikoko inplikazio totala $t=-2.274 ; p=.025)$. Bi horietan mutilak dira balio altuenak lortu dituztenak.

Kirol-jarduera fisikoaren intentsitatearen efektua aztertzeko hurrengo ANOVA proba aurkezten da (ikusi 6. taula). Jakina denez, analisi honetarako soilik kirol-jarduera fisikoa praktikatzen zuten horiek kontuan hartu dira, hain zuzen ere laginaren $\% 92$.

6. taula

Kirol-jarduera fisikoaren inplikazioa jarduera fisikoaren intentsitatearen arabera

\begin{tabular}{|c|c|c|c|c|c|c|c|}
\hline & & $\mathrm{N}$ & M & SD & $\mathrm{F}$ & $\mathrm{P}$ & Post-hoc (P) \\
\hline Afektua & $\begin{array}{l}\text { Baxua } \\
\text { Ertaina } \\
\text { Altua }\end{array}$ & $\begin{array}{l}20 \\
53 \\
19\end{array}$ & $\begin{array}{l}18.75 \\
18.18 \\
19.00\end{array}$ & $\begin{array}{l}1.48 \\
2.04 \\
1.41\end{array}$ & 1.669 & .194 & \\
\hline Kognizioa & $\begin{array}{l}\text { Baxua } \\
\text { Ertaina } \\
\text { Altua }\end{array}$ & $\begin{array}{l}20 \\
53 \\
19\end{array}$ & $\begin{array}{l}13.75 \\
13.86 \\
14.36\end{array}$ & $\begin{array}{l}1.80 \\
1.49 \\
1.25\end{array}$ & .967 & .384 & \\
\hline Jarrera & $\begin{array}{l}\text { Baxua } \\
\text { Ertaina } \\
\text { Altua }\end{array}$ & $\begin{array}{l}20 \\
53 \\
19\end{array}$ & $\begin{array}{r}10.35 \\
9.83 \\
11.73\end{array}$ & $\begin{array}{l}3.80 \\
2.51 \\
2.74\end{array}$ & 3.059 & .052 & \\
\hline $\begin{array}{c}\text { Imnplikazio } \\
\text { Totala }\end{array}$ & $\begin{array}{l}\text { Baxua } \\
\text { Ertaina } \\
\text { Altua }\end{array}$ & $\begin{array}{l}20 \\
53 \\
19\end{array}$ & $\begin{array}{l}42.85 \\
41.88 \\
45.10\end{array}$ & $\begin{array}{l}5.25 \\
4.04 \\
4.20\end{array}$ & 3.816 & $.026^{*}$ & $\begin{array}{c}\text { Ertain-Altua } \\
\mathbf{. 0 1 9} *\end{array}$ \\
\hline
\end{tabular}

Taulan azaltzen den moduan, soilik kirol-inplikazio totalean $(p=.026)$ daude ezberdintasun adierazgarriak. Horrela, horren batezbestekoan ezberdintasunak daudela frogatuta, post-hoc probak burutzen dira, horietatik zein desberdintzen den zehazteko. Kasu honetan, taulan adierazi denez, intentsitate ertain-altuan $(p=.019)$ ezberdintasun adierazgarriak daude.

\section{ONDORIOAK}

Lan honen helburu nagusia aurreko ikerketa batetik sortzen da (Izar de la Fuente et al., 2018). Lan horren etorkizuneko eginbeharren artean, item baten ezabapenaren bidez galdeketaren barne trinkotasunaren hobekuntza eta neurketa tresnaren egitura baieztatuko lukeen faktore-analisi baieztatzailearen garapena planteatzen zen. 
Horrela, kirol-jarduera fisikoko inplikazioaren galdeketaren Lehen Hezkuntzarako lehenengo baliozkotzetik abiatuta, horren berrikusketa egitea, barne trinkotasuna hobetzea eta faktore-analisi baieztatzailea helburu nagusi gisa zehaztu dira ikerketa honetan.

Lorturiko emaitzak egokitzat har daitezke; izan ere, lehenengo baliozkotzearen barne trinkotasuna handitzea lortu da bi item baztertu arren. Izan ere, Cronbach-eko alfan item kopuru handiak modu positiboan eragiten du (Muñoz, 2009). Hala ere, Cronbach-eko alfak ez du fidagarritasunik adierazten (Carretero-Dios, 2005). Hori dela eta, fidagarritasun konposatuko koefizientea (Composite Reliability Coefficient, CRC) eta laburtutako batezbesteko bariantza (Average Variance Extracted, AVE) aztertu behar dira. Ikerketa honetan, lehenengoa egokia izan da, ez ordea bigarrena. Hala ere, azken hori onartutako mugatik oso hurbil geratu da.

Horretaz gain, lehenengo baliozkotze pilotuarekin alderatuta, bi item gutxiagoko eskala izanda ere, bariantza totalaren portzentajea handiagoa izan da. Hortaz, mantendutako hamar item horiek oso ondo zehaztuta daudela baiezta daiteke; izan ere, itemak kanporatzean/baztertzean azalpengaitasuna galdu ohi da.

Barne trinkotasuna eta azaldutako bariantza totalaren portzentajea IMAF (Infante et al., 2015) galdeketa originalean lortutako emaitzekin alderatuta baxuagoak izan arren, ikerketa honetan lortutako indizeak egokiak dira.

Faktore-analisi aztertzailean lorturiko galdeketaren azkeneko egitura ere egokia izan da, izan ere, item guztiek bere faktorean asetu dute gutxieneko pisu faktoriala errespetatuz (Lozano eta De la Fuente, 2009; Morales, 2011), hiru dimentsiotan banatuta.

Azken egitura hori faktore-analisi baieztatzailearekin aztertu da, lortutako emaitzak positiboak izanez. Izan ere, galdeketaren egitura tridimentsionala egitura egokiena bezala nabarmendu da. Horretaz gain, tridimentsionaltasun horrek bat egin du Fredricks et al.ek (2004) planteatutako inplikazioaren ereduarekin, baita Infante et al.ek, (2015) kirol-jarduera fisikorako planteatutakoarekin ere. Hortaz, berriz ere inplikazioaren barne egitura tridimentsionala baieztatzen da.

Ikerketaren bigarren helburu moduan, aldagai soziopertsonalen (sexua eta kirol-jarduera fisikoko inplikazioa) arabera galdeketak duen aldagarritasuna aztertu da. Kirol-jarduera fisikoko testuinguruan inplikazioaren analisia ikerketa lerro aitzindaria izanda, ez dago gaiaren inguruko informazio handirik (Izar de la Fuente et al., 2018). Horren ondorioz, kirol-jarduera fisikoko inplikazioaren inguruko hipotesien oinarri gisa, teorikoki hurbila den aldagai bat erabili da: autokontzeptu fisikoa.

Horrela, ikerketa honen emaitzetan adierazi denez, mutilek neskek baino kirol-jarduera fisikoko inplikazio maila altuagoa dute. Datu hori bat dator autokontzeptu fisikoan gizonen aldeko ezberdintasunak adierazten dituzten ikerketekin (Goñi, et al. 2004; Crain, 1996, Ayora, et al., 1997; Garduño eta Ramírez, 2001). 
Jarduera fisikoaren intentsitateari dagokionez, ikerketa honetan, intentsitate altuak intentsitate ertaina edo baxua baino inplikazio maila altuagoa adierazi du. Lorturiko emaitza hori bat dator Revuelta, Esnaola eta Goñi (2016) egileek adierazi zuten baieztapenarekin; izan ere, horien arabera, intentsitatea zenbat eta altuagoa izan, orduan eta positiboagoa da autopertzepzio fisikoa.

Ikerketaren emaitzak egokitzat har daitezkeen arren, etorkizunari begira badaude hobetu beharrekoak. Horrela, nahiz eta galdeketaren balioztatzearen indizeak egokiak izan, inplikazioaren dimentsio guztien inguruko item gehiago sortzea gomendatzen da, laburtutako batezbesteko bariantza gomendatutako mugara hel dadin. Hala eta guztiz ere, galdeketak kirol-jarduera fisikoko inplikazioa Lehen Hezkuntzan detektatzeko modu egokian funtzionatzen du.

Amaitzeko, ikerketa burutzerako garaian egondako mugak zehaztea beharrezkoa da. Horrela, kontuan hartu behar da baliozkotze honetarako erabili den parte-hartzaile kopurua murriztua izan dela. Hori dela eta, baliozkotze prozesua lagin handiagoarekin antolatu beharko litzateke aurrerantzean.

\section{ERREFERENTZIAK}

Ayora, D., García, A., eta Rubio, S. (1997). Factores del autoconcepto relacionados con el rendimiento de los adolescentes en educación física. Revista de Psicología del Deporte, 12, 59-73.

Balaguer, I., Atienza, F.L., eta Duda, J.L. (2012). Self-perceptions, self-worth and sport participation in adolescents. The Spanish Journal of Psychology, 15(2), 624-630.

Bevans, K., Fitzpatrick, L.A., Sanchez, B., eta Forrest, C. B. (2010). Individual and instructional determinants of student engagement in physical education. Journal of teaching in physical education, 29(4), 399-416.

Biddle, S.J.H., Whitehead, O'Donovan, T. M., eta Nevill, M. E. (2005). Correlates of participation in physical activity for adolescent girls: A systematic review of recent literature. Journal of Physical Activity and Health, 2, 423-435.

Browne M.W., eta Cudeck R. (1992). Alternative ways of assessing model fit. Sociological Methods Research, 21, 230-258. doi: 10.1177/0049124192021002005

Carretero-Dios, H., eta Pérez, C. (2005). Normas para el desarrollo y revisión de estudios instrumentales. International Journal of Clinical and Health Psychology, 5(3), 521-551.

Chok, N.S. (2010) Pearson's versus Spearman's and Kendall's Correlation Coefficients for Continuous Data. Tesi doktorala. Pittsburgh: Pittsburgh-eko unibertsitatea.

Crain, M. (1996). The influence of age, race and gender on child and adolescent selfconcept. B. A. Bracken-en (Ed.), Hanbook of self-concept. (395-420 orr.). New York: Wiley. 
Iker Izar de la Fuente, Arantzazu Rodríguez, Naiara Escalante

Crocker, P., Eklund, R.C., eta Kowalski, K.C. (2000). Children's physical activity and physical self-perceptions. Journal of Sports Sciences, 18, 383-394.

Edgell, S.E., eta Noon, S.M. (1984). Effect of violation of normality on the test of the correlation coefficient. Psychological Bulletin, 95(3), 576-583.

Elosua, P. (2004). Autokontzeptu-eskalaren euskaratzea. Tantak: Euskal Herriko Unibertsitateko hezkuntza aldizkaria, 32, 39-55.

Esnaola, I. (2005). Elaboración y validación del cuestionario Autokontzeptu Fisikoaren Itaunketa (AFI) de autoconcepto físico. Tesi doktorala. Leioa: Euskal Herriko Unibertsitatea.

Finn, J.D. (1989). Withdrawing from school. Review of Educational Research, 59(2), 117-142.

Fredricks, J.A., Blumenfeld, P.C., eta Paris, A.H. (2004). School engagement: Potential of the concept, state of the evidence. Review of Educational Research, 74(1), 59-109.

Garduño, L., eta Ramírez, M. R. (2001). Evaluación de la autoestima en una muestra de niños de primaria de escuelas públicas y privadas. Revista de Investigación Educativa, 19(1), 183-198.

Goñi, A., Ruiz de Azúa, S., eta Rodríguez, A. (2004). Deporte y autoconcepto físico en la preadolescencia. Apunts. Educación Física y Deportes, 3(77), $18-24$.

Goñi, A., Ruiz de Azúa, S., eta Rodríguez, A. (2006). Cuestionario de Autoconcepto Físico $(C A F)$. Madrid: EOS.

González, M.T. (2010). El alumno ante la escuela y su propio aprendizaje: algunas líneas de investigación en torno al concepto de implicación. Revista Iberoamericana sobre Calidad, Eficacia y Cambio de Educación, 8(4), 11-31.

Hair, J.F., Anderson, R.E., Tatham, R.L., eta Black, W.C. (2004). Análisis Multivariante. Madril: Pearson.

Hair, J.F., Black, W.C., Babin, B.J., Anderson, R.E., eta Tatham, R.L. (2006). Multivariate date analysis. Upper Saddle River, NJ: Pearson Prentice Hall.

Hu, L., eta Bentler, P.M. (1999). Cutoff criteria for fit indexes in covariance structure analysis: Conventional criteria versus new alternatives. Structural Equation Modeling, 6(1), 1-55. doi: 10.1080/10705519909540118

Inchley, J., Kirby, J., eta Currie, C. (2011). Longitudinal changes in physical selfperceptions and associations with physical activity during adolescence. Pediatric Exercise Science, 23, 237-249.

Infante, G., Rodríguez, A., Fernández, A., eta Goñi, E. (2007) Autoconcepto físico y práctica deportiva en edad adulta. J. Castellano eta O. Usabiaga-n (Edk.), Investigación en la Actividad Física y el Deporte II (40-58 orr.). Bilbo: Euskal Herriko Unibertsitatea. ISBN: 84-611-4105-9.

Infante, G., Zuazagoitia, A., Revuelta, L., eta Echeazarra, I. (2015). Propiedades psicométricas de un nuevo cuestionario de implicación en la actividad físicodeportiva. En II Congreso Internacional de Ciencias de la Educación y del Desarrollo. 24-26 de junio de 2015. San Sebastián.

Izar de la Fuente, I., Rodríguez, A., eta Revuelta, L. (2018). Inplikazioa jarduera fisikoan Lehen Hezkuntzan: neurketa eta aldagarritasuna. C. Arriaga eta A., Romero-n, (edk.). XXIV Jornadas de Investigación en psicodidáctica. XXIV Psikodidaktikako Ikerkuntza Jardunaldiak (299-317 orr.). Leioa: UPV/ EHUko argitalpen zerbitzua. ISBN 978-84-9082-837-3. 
Jaakkola, T., eta Washington, T. (2011). Measured and perceived physical fitness, intention, and self-reported physical activity in adolescence. Advances in Physical Education, 1(2), 16-22.

Lacobucci, D. (2010). Structural equations modeling: Fit indices, sample size, and advanced topics. Journal of Consumer Psychology, 20(1), 90-98. doi:10.1016/j.jcps.2009.09.003

Leithwood, K., eta Jantzi, D. (1998). Distributed leadership and student engagement in school. Annual meeting of the American educational research association. San Diego

Leithwood, K., Mulford, W., eta Silins, H. (2004). Educational leadership for organisational learning and improved student outcomes. Kluwer Academic Publishers. Dordrecht/Boston /London.

Lozano, L., eta De la Fuente-Solana, E. (2009). Diseño y validación de cuestionarios. Pantoja-Vallejo-n (Coord.), Manual básico para la realización de tesinas, tesis y trabajos de investigación-en (251-274 or.). Madril: EOS.

Marks, H. (2000). Student engagement in instructional activity: Patterns in elementary, middle and high school years. American Educational Research Journal, 37, 153-184.

Morales, P. (2011). El análisis factorial en la construcción e interpretación de tests, escalas y cuestionarios. Madrid: Universidad Pontificia Comillas.

Muñoz, M.J. (2009). Análisis de la situación de salud de los alumnos de la Universidad de Almería según el método precede-proceed. Un proyecto de educación para la salud. Tesi doktorala. Almeria: Almeriako unibertsitatea.

Newmann, L., eta Davies, E. (1992). The school engagement of elementary and middle school students with disabilities. AA.VV.-n (Edk.), Engagement, academics, social adjustment and independence: The achievement of elementary and middle school students with disabilities (1-18 or.). California: Menlo Park.

Nunnally, J.C., eta Bernstein, I. J. (1995). Teoría psicométrica. Madril: McGrawHill

Nunnally, J C. (1967). Psychometric theory. New York: McGraw-Hill.

Peterson, R.A., eta Kim, Y. (2013). On the relationship between coefficient alpha and composite reliability. Journal of Applied Psychology, 98(1), 194-198. doi: $10.1037 / \mathrm{a} 0030767$

Ramos, E. (2015). Resiliencia y ajuste psicosocial en la adolescencia. Tesi doktorala. Leioa: Euskal Herriko Unibertsitatea.

Ramos, E., Fernández, A., Zuazagoitia A., Rodríguez, A., eta Ros, I. (2015). Eskola-inplikazioa: kontzeptua, neurketa, aldakortasuna eta testuinguruaren aldagaiak nahiz aldagai psikologikoak. Tantak: Euskal Herriko Unibertsitateko hezkuntza aldizkaria, 27(2), 149-168.

Revuelta, L., Esnaola, I., eta Goñi, A. (2016). Relaciones entre el autoconcepto físico y la actividad físico-deportiva adolescente. Revista Internacional de Medicina y Ciencias de la Actividad Física y el Deporte, 16(62),561-581.

Rodríguez, A., Axpe, I., eta Goñi, A. (2015). Propiedades psicométricas de una versión abreviada del Cuestionario de Autoconcepto Físico (CAF). Actas Esp Psiquiatr, 43(4), 125-132.

Rodríguez, A., Droguett, L., eta Revuelta, L. (2012). School and Personal Adjustment in Adolescence: The Role of Academic Self-concept and Perceived Social Support. Revista de Psicodidáctica, 17(2), 397-414. 
Rodríguez, A., Ramos, E., Fernández, A., Goñi, E., Esnaola, I., eta Goñi A. (2016). Contextual and psychological variables in a descriptive model of subjective well-being and school engagement. International Journal of Clinical and Health Psychology, 16(2), 166-174. doi:10.1016/j.ijchp.2016.01003.

Rodríguez, A.; Ramos, E., Ros, I., eta Zuazagoitia, A. (2018). Implicación escolar de estudiantes de secundaria: La influencia de la resiliencia, el autoconcepto y el apoyo social percibido. Educación XX1, 21(1), 87-108. doi: 10.5944/educXX1.16026

Ros, I. (2009). La implicación del estudiante con la escuela. Revista de Psicodidáctica, 14(1), 79-92.

Ros, I., Goikoetxea, J., Gairín, J., eta Lekue, P. (2012). Implicación del alumnado en la escuela: Diferencias interindividuales e intercentros. Revista de Psicodidáctica, 17(2), 291-307. doi: 10.1387/Rev.Psicodidact.4496

Ros, I., eta Zuazagoitia, A. (2015). Implicación escolar y autoconcepto. A. Fernández eta L. Revuelta-n (Edk.), Ajuste personal y social. Investigación psicoeducativa (119-129 or.). San Sebastian: Erein.

Ruiz de Auza, S., Zulaika, L. M., Palacios, S., eta Goñi, A. (2002). Autokontzeptu fisikoa nerabezaroan eta bere eremuak. Tantak: Euskal Herriko Unibertsitateko hezkuntza aldizkaria, 28, 35-50.

Schmider, E., Ziegler, M., Danay, E., Beyer, L., eta Bühner, M. (2010). Is it really robust? Reinvestigating the robustness of ANOVA against violations of the normal distribution assumption. Methodology, 6(4), 147-151. doi: 10.1027/1614-2241/a000016

Schumacker, R.E., eta Lomax, R.G. (2010). A beginner's guide to structural equation modeling. New York, NY, US: Routledge/Taylor \& Francis Group.

Tomás, J.M., y Oliver, A. (1997). Efectos de formato de respuesta y método de estimación en análisis factorial confirmatorio. Psicothema, 10(1), 197-208.

Wehlage, G.G., Rutter, R.A., Smith, G.A., Lesko, N., eta Fernandez, R.R. (1989). Reducing the risk: Schools as communities of support. Philadelphia: Falmer Press. 


\section{ERANSKINAK}

\section{Lehen Hezkuntzarako IMAF galdeketaren itemak}

\begin{tabular}{|c|c|c|c|c|c|c|}
\hline 1 & Me gusta la actividad físico-deportiva & & 2 & 3 & 4 & \\
\hline 4 & Me siento a gusto practicando actividad físico-deportiva & 1 & 2 & 3 & 4 & 5 \\
\hline 5 & $\begin{array}{l}\text { Busco información relativa a la actividad físico-deportiva } \\
\text { que practico }\end{array}$ & 1 & 2 & 3 & 4 & 5 \\
\hline 7 & $\begin{array}{l}\text { Me siento bien después de hacer actividad físico-depor- } \\
\text { tiva }\end{array}$ & 1 & 2 & 3 & 4 & 5 \\
\hline 8 & $\begin{array}{l}\text { Utilizo la actividad físico-deportiva como medio de libe- } \\
\text { ración de tensiones }\end{array}$ & 1 & 2 & 3 & 4 & 5 \\
\hline 10 & Disfruto haciendo actividad físico-deportiva & 1 & 2 & 3 & 4 & 5 \\
\hline 11 & $\begin{array}{l}\text { Creo que practicar actividad físico-deportiva es útil para } \\
\text { mi vida diaria }\end{array}$ & 1 & 2 & 3 & 4 & 5 \\
\hline 17 & $\begin{array}{l}\text { Pienso que practicar actividad físico-deportiva es bueno } \\
\text { para mi salud }\end{array}$ & & 2 & 3 & 4 & 5 \\
\hline 19 & $\begin{array}{l}\text { Practico actividad físico-deportiva } 3 \text { veces por semana } \\
\text { como mínimo }\end{array}$ & 1 & 2 & 3 & 4 & 5 \\
\hline 22 & $\begin{array}{l}\text { Creo que la actividad físico-deportiva ayuda a mi bienes- } \\
\text { tar personal }\end{array}$ & & 2 & 3 & 4 & \\
\hline
\end{tabular}

